Journal of Fundamental and Applied Sciences

ISSN 1112-9867

Available online at

http://www.jfas.info

\title{
ELECTROCHEMISTRY CHARACTERIZATION OF FERROCENE/FERRICENIUM REDOX COUPLE AT GLASSY CARBON ELECTRODE
}

\author{
N. S. Neghmouche, A. Khelef and T. Lanez
}

Institute of sciences and technology, University Centre of El-Oued, B.P.789, 39000, El-Oued, Algeria

Received: 25 November 2009 / Accepted: 06 December 2009 / Published online: 31 December 2009

\begin{abstract}
In the present work the oxidation of ferrocene, $\mathrm{Fe}\left(\mathrm{C}_{5} \mathrm{H}_{5}\right)_{2}$, to the ferrocenium cation, $\mathrm{Fe}\left(\mathrm{C}_{5} \mathrm{H}_{5}\right)_{2}^{+}$, was examined in the solvents dichloromethane, and aqueous ethanol using the technique of cyclic voltammetry. The anodic $\left(E_{\mathrm{pa}}\right)$ and the cathodic $\left(E_{\mathrm{pc}}\right)$ peak potentials, as well as the corresponding anodic $\left(i_{\mathrm{pa}}\right)$ and cathodic $\left(i_{\mathrm{pc}}\right)$ peak currents, were obtained at different scan rates $\left(0.05,0.10,0.30,0.50 \mathrm{~V} . \mathrm{s}^{-1}\right)$. The diffusion coefficients $(D)$ have been calculated using the Randles-Sevcik equation. The effects of changing the scan rate on the electrochemical behavior of ferrocene have been examined.
\end{abstract}

Keywords: Cyclic voltammetry, diffusion coefficient, ferrocene, half-wave potential, Randles-Sevcik equation.

\section{INTRODUCTION}

Bis(cyclopentadienyl)iron(II) or ferrocene, $\mathrm{Fe}\left(\mathrm{C}_{5} \mathrm{H}_{5}\right)_{2}$ is one of the most studied organometallic molecules. It has a sandwich structure with the iron sandwiched between two cyclopentadienyl rings. Additionally, it is a well established [1-3] one-electron donor $(\mathrm{n}=1)$. The independently 1951 discovery of ferrocene by Pauson and Miller revolutionized the area of organometallic chemistry[4,5].

Author Correspondence, e-mail: t_lanez@yahoo.fr

ICID: 1040454 
The 1973 Nobel Prize in Chemistry was awarded to Wilkinson and Fischer for elucidation of its structure [1] figure (1). This led to greater interest in d-block metal-carbon bonds and brought about the development of organometallic chemistry.
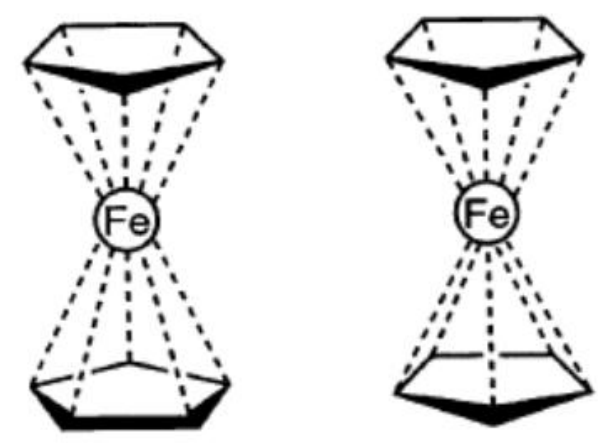

Fig.1. The sandwich structure of ferrocene

\section{Electrochemical proprieties}

It is well known that ferrocene easily undergoes one electron oxidation to form ferrocenium cation $\mathrm{Fe}\left(\mathrm{C}_{5} \mathrm{H}_{5}\right)_{2}^{+}$in a reversible manner[6-9] figure (2). Thus, we investigated the ferrocene electrochemical behaviors in organic and aqueous mediums.

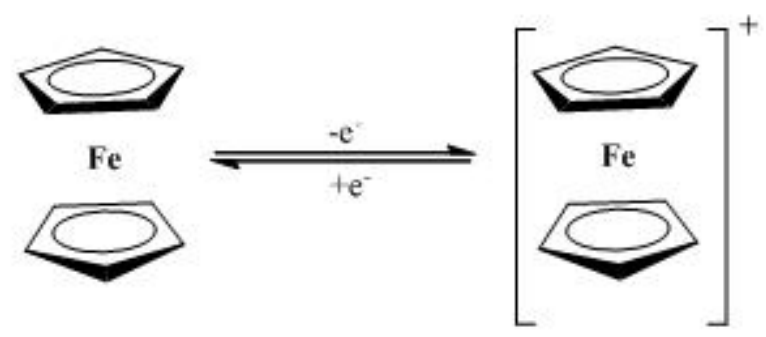

Fig.2. Reversible mono electronic oxidation of ferrocene

\section{EXPERIMENTAL}

\section{Chemicals}

Ferrocene (Fluka, 98\% purity) and sulfuric acid (Fluka, 99\% purity ) were used as received, the electrolyte salt tetrabutylammonium tetrafluoroborate $\mathrm{Bu}_{4} \mathrm{NBF}_{4}$ (Fluka, electrochemical grade $99 \%$ purity) was dried for $1 \mathrm{~h}$ at $105{ }^{\circ} \mathrm{C}$ before use. Dichloromethane (Sigma-Aldrich, 99.9\% purity) was dried over molecular sieves before use. Argon plunging tube bottle was provided by ENGI (Enterprise nationale des gaz 
industriels). All the freshly prepared solutions were degassed under argon gas flow before experiments.

\section{RESULTS AND DISCUSSION}

\section{Electrochemical measurement on a fixed electrode}

Electrochemical characterization was carried out on a potentiostat type voltalab 40 of radiometer, with a three-stand electrode cell. Cyclic voltammetric experiments were performed in deoxygenated $\mathrm{CH}_{2} \mathrm{Cl}_{2}$ and aqueous ethanol solutions of ferrocene with respectively $10^{-1} \mathrm{M}$ of $\mathrm{Bu}_{4} \mathrm{NBF}_{4}$ and $\mathrm{H}_{2} \mathrm{SO}_{4}$ as supporting electrolyte and ferrocene concentration of $10^{-3} \mathrm{M}$. The three electrodes used were glassy carbon disk as the working electrode, saturated calomel electrode as a reference electrode, and Pt wire as an auxiliary electrode. The working electrode was polished with $0.05 \mu \mathrm{m}$ alumina slurry for $1-2$ minutes, and then rinsed with double-distilled and deionized water. This cleaning process is done before each cyclic voltammetry experiment and a sweep between 0 and $2000 \mathrm{mV}$ is performed on the electrolyte solution to detect any possible deposition of ferrocene on the electrode surface.

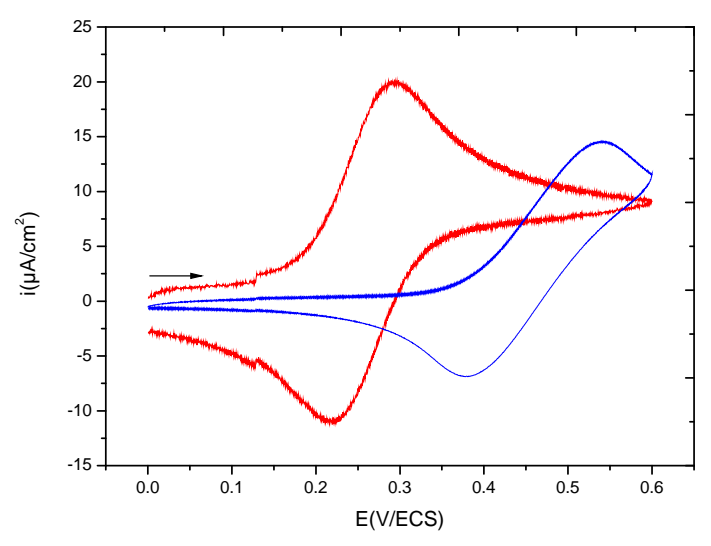

Fig.3. cyclic voltammetry of ferrocene $1 \mathrm{mM}$ and $100 \mathrm{mM} \mathrm{Bu}_{4} \mathrm{NBF}_{4}$ in $\mathrm{CH}_{2} \mathrm{Cl}_{2}$ (bleu) and $1 \mathrm{mM}$ of ferrocene in ethanol/aq. $\mathrm{H}_{2} \mathrm{SO}_{4}(\mathrm{red})$ at $2 \mathrm{~mm}$ diameter glassy carbon working electrode, Pt counter electrode, and CSE reference electrode at $0.50 \mathrm{~V} . \mathrm{s}^{-1}$.

Figure 3 shows a glassy carbon electrode voltammetry of ferrocene in organic medium $\left(\mathrm{CH}_{2} \mathrm{Cl}_{2}\right)$ and aqueous medium (ethanol/aq. $\left.\mathrm{H}_{2} \mathrm{SO}_{4}\right)$. The peak potential spacing ( Ep) is $0.162 \mathrm{~V}$ for the ferrocene in $\mathrm{CH}_{2} \mathrm{Cl}_{2}$ and $0.074 \mathrm{~V}$ for the ferrocene in ethanol/aq. $\mathrm{H}_{2} \mathrm{SO}_{4}$. A fast, reversible, one-electron transfer would ideally have a $\mathrm{Ep}=0.059 \mathrm{~V}$ at $298 \mathrm{~K}$ 
[10]. The discrepancy from this ideal value is attributed to slow electron transfers and solution resistance.

On glassy carbon electrode, the difference in peak potential spacing between ferrocene in organic medium and ferrocene in aqueous medium is roughly equal to $88 \mathrm{mV}$. This observation is related to the difference in diffusion coefficient between ferrocene in each medium (major contributor). Additionally, there is a difference in the viscosity of the two electrochemical medium (minor contributor), which is related to solution resistance (a more viscous solvent will have a higher solution resistance).

In order to investigate the mechanism of oxidation and reduction of ferrocene in organic and aqueous medium solution on both studied electrodes, voltammetry cyclic were recorded in $1 \mathrm{mM}$ solution of ferrocene in both medium at different scanning rate. The obtained voltammogrammes are shown in figure 4.
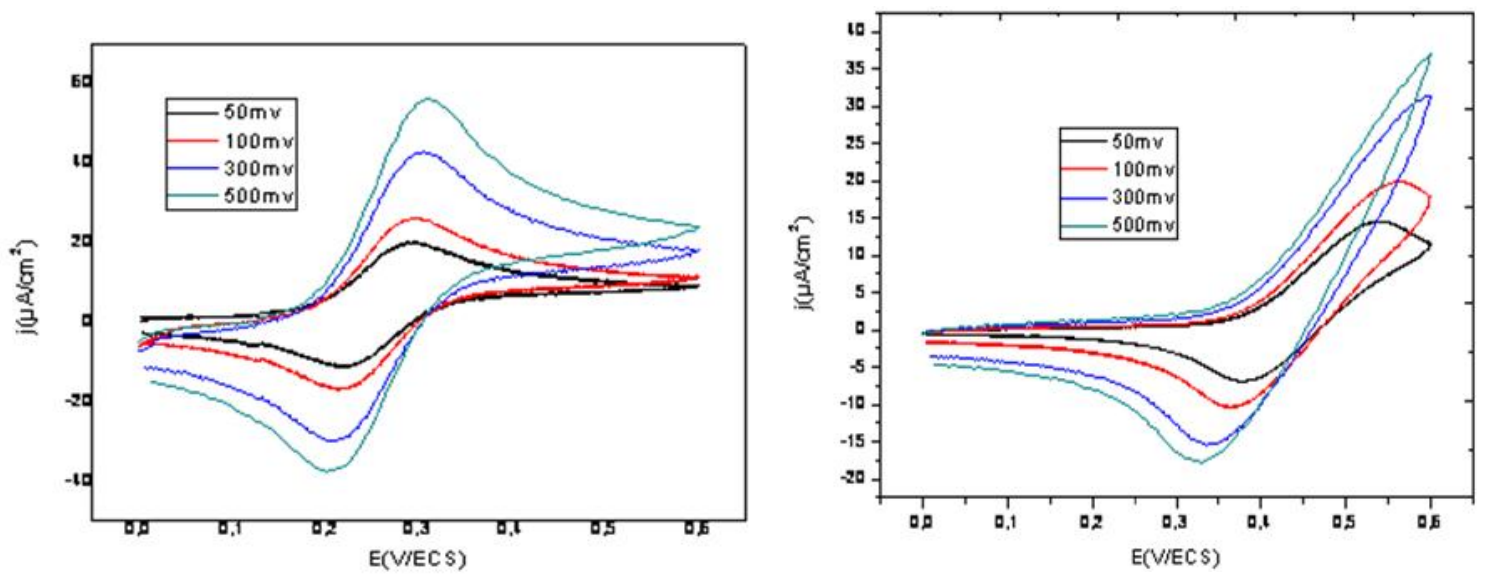

Fig.4. Cyclic voltammetry of ferrocene $1 \mathrm{mM}$ and $100 \mathrm{mM} \mathrm{Bu} \mathrm{NBF}_{4}$ in $\mathrm{CH}_{2} \mathrm{Cl}_{2}$ (bleu) and $1 \mathrm{mM}$ of ferrocene in ethanol/aq. $\mathrm{H}_{2} \mathrm{SO}_{4}$ (red) at $2 \mathrm{~mm}$ diameter glassy carbon working electrode, Pt counter electrode, and CSE reference electrode at

$$
\left(0.05,0.10,0.30,0.50 \mathrm{~V} . \mathrm{s}^{-1}\right) \text {. }
$$

The anodic and the cathodic peak heights as function of the square root of the scanning rate for conventional glassy carbon are shown in figure 5. The obtained linear relationship indicates clear diffusion character. As it can be seen from the figures, the ratio of the anodic and cathodic current peak heights is close to one; this indicates the reversible character of the oxidation of ferrocene in both studied medium. 

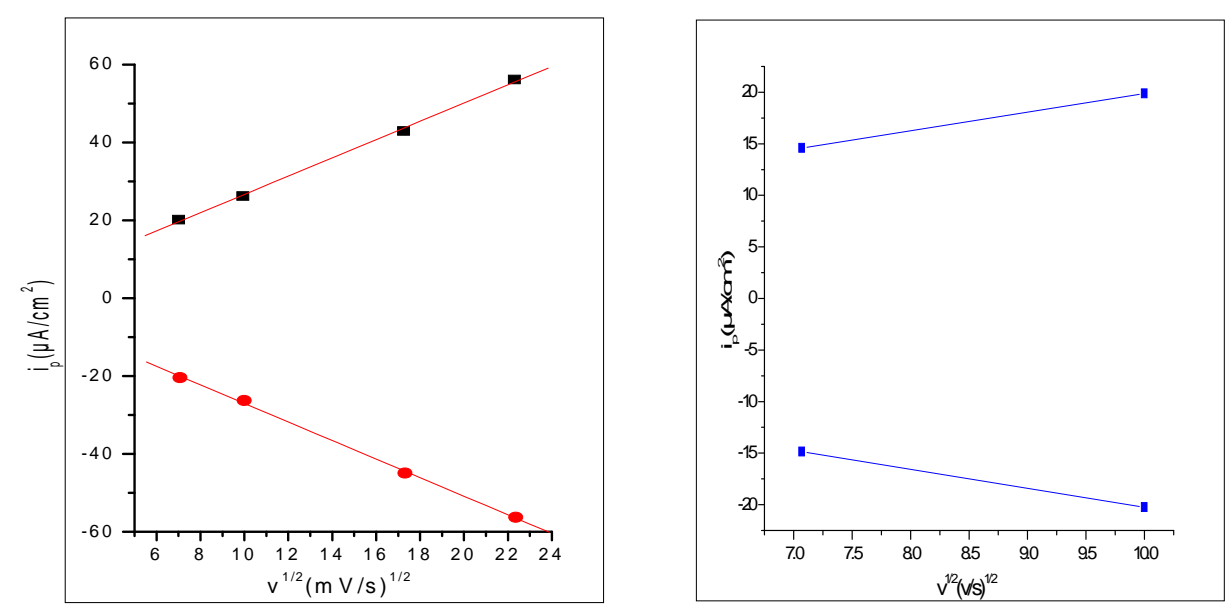

Fig.5. The anodic and the cathodic peak heights as function of the square root of the scanning rate for conventional glassy carbon in $\mathrm{CH}_{2} \mathrm{Cl}_{2}$ (bleu) and in ethanol/aq. $\mathrm{H}_{2} \mathrm{SO}_{4}$ (red) at $2 \mathrm{~mm}$ diameter Pt working electrode.

\section{Electrochemical measurement on Rotating Disk electrode}

The diffusion coefficient and the thickness of the diffusion layer of ferrocene in organic and aqueous medium were measured using the same conditions as used for voltammetry cyclic.

The calculations were based on the Randles-Sevcik equation. That means the anodic peak height of ferrocene oxidation (obtained from voltammetry cyclic measurements) was measured in quiescent solutions on both electrodes and in both medium.
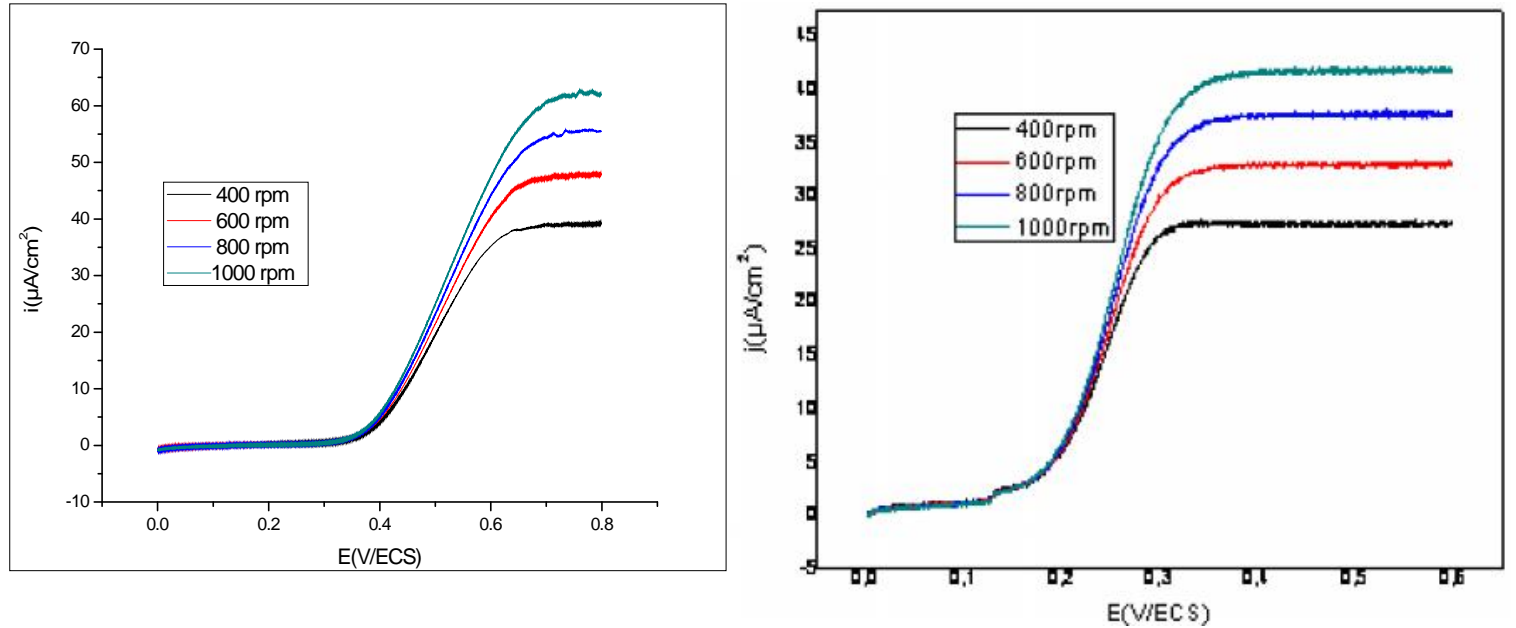

Fig.6. Polarogramme of ferrocene $1 \mathrm{mM}$ and $100 \mathrm{mM} \mathrm{Bu} 4 \mathrm{NBF}_{4}$ in $\mathrm{CH}_{2} \mathrm{Cl}_{2}$ (bleu) and $1 \mathrm{mM}$ of ferrocene in ethanol/aq. $\mathrm{H}_{2} \mathrm{SO}_{4}$ (red) at $2 \mathrm{~mm}$ diameter glassy carbon working 
electrode, Pt counter electrode, and CSE reference electrode at $0.50 \mathrm{~V} . \mathrm{s}^{-1}$. (rotating rate:400,600, 800, $1000 \mathrm{rpm})$
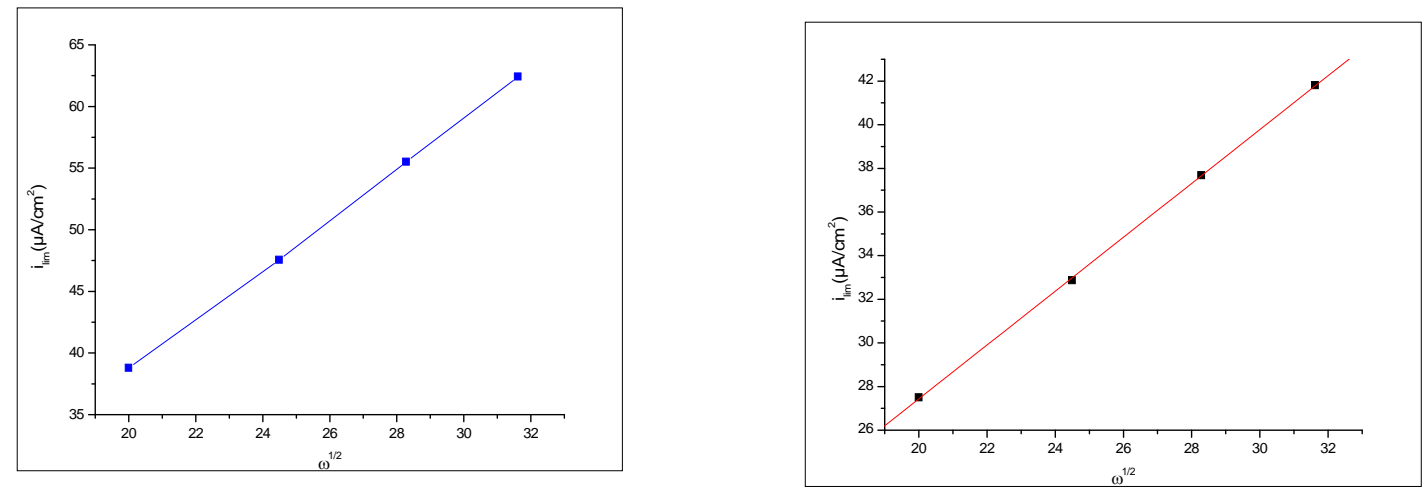

Fig.7. The diffusion current as function of the square root of the rotating rate for glassy carbon in $\mathrm{CH}_{2} \mathrm{Cl}_{2}$ (bleu) and in ethanol/aq. $\mathrm{H}_{2} \mathrm{SO}_{4}$ (red)

The coefficient diffusion is calculated as follows:

The thickness of the layer of diffusion $\delta(\mathrm{cm})$, is given by the equation of Levich:

$$
\delta=0.645 D_{O x}^{\frac{1}{3}} \gamma^{\frac{1}{2}} \omega^{-\frac{1}{2}}
$$

$\mathrm{D}_{\mathrm{ox}}$ : The coefficient diffusion $\left(\mathrm{cm}^{2} . \mathrm{s}^{-1}\right)$

$\omega$ : Rotating rate of the electrode $\left(\mathrm{rad} . \mathrm{s}^{-1}\right)$

$\gamma$ : Cinematic viscosity $\left(\mathrm{cm}^{2} \cdot \mathrm{s}^{-1}\right)$ (the ratio of the viscosity to the density)

For the chloromethane the viscosity and the density are respectively equal to $0.43 \mathrm{mPa}$.s and 1.328 which gives $\gamma=0.0323 \mathrm{~cm}^{2} . \mathrm{s}^{-1}$.

For an aqueous solution, the cinematic viscosity is $\gamma=10^{-2} \mathrm{~cm}^{2} \cdot \mathrm{s}^{-1}$.

From Figure 7 the slope of the line gives

$$
P=\frac{i}{\omega^{\frac{1}{2}}}
$$

On another hand the limited current is given by,

$$
i=\frac{n F A D C}{\delta}
$$

Where as:

$\mathrm{n}$, number of electrons

$\mathrm{F}$, is the Faraday $\left(9.65 .10^{4} \mathrm{C} / \mathrm{mol}\right)$

$\mathrm{A}$, is the area of the working electrode $\left(\mathrm{cm}^{2}\right)$.

$\mathrm{D}$, is the coefficient diffusion $\left(\mathrm{cm}^{2} \cdot \mathrm{s}^{-1}\right)$ 
$\mathrm{C}$, is the concentration $\left(\mathrm{mol} / \mathrm{cm}^{3}\right)$, in our case is equal to $10^{-3} \mathrm{~mol} / 1$

Replacing equations 2 and 3 in 4 gives,

$$
D^{\frac{2}{3}}=\frac{P 1.61 \gamma^{\frac{1}{6}}}{n F A C \sqrt{2 \pi}}
$$

For a rotating rate of the working electrode equal to $400 \mathrm{t} / \mathrm{min}$, D is.

$$
D=19.21 \times 10^{-6} \mathrm{~cm}^{2} \cdot \mathrm{s}^{-1}
$$

Replacing the value of $\mathrm{D}$ in equation 1 gives

\begin{tabular}{|c|c|c|c|}
\hline Medium & $\bar{D}$ & $0 \times \mathrm{cm}^{2} / \mathrm{s}$ & $\underset{\delta(n)}{\mathrm{n})}$ \\
\hline $\mathrm{CH}_{2} \mathrm{Cl}_{2}$ & 1.95 & 77.27 & 345.35 \\
\hline ethanol/aq. $\mathrm{H}_{2} \mathrm{SO}_{4}$ & 1.34 & 32.82 & 260.91 \\
\hline
\end{tabular}

$$
\delta=219.81 \mathrm{~nm}
$$

\section{CONCLUSION}

Based on the peak potential spacing ( $\mathrm{Ep}$ ), the solution resistance of $\mathrm{CH}_{2} \mathrm{Cl}_{2}$ and in aq. ethanol toward ferrocene has been studied, the results obtained show that Ep for both solvents are grater than the ideal value for a fast, reversible, one-electron transfer. The discrepancy can be attributed to slow electron transfers and solution resistance. In addition Ep for the ferrocene in $\mathrm{CH}_{2} \mathrm{Cl}_{2}$ is grater than Ep in aq. ethanol, this difference can be attributed to the difference in diffusion coefficient between ferrocene in each medium which is a major contributor. However there is a minor contributor which is related to the difference in the solution resistance of the two electrochemical medium.

\section{ACKNOWLEDGMENTS}

Support of the work by the laboratoire de valorisation et promotion des resources sahariennes is gratefully acknowledged. We would like to thank Professor M. SAIDI, for his help.

\section{REFERENCES}

[1] Wilkinson G., Rosenblum M., Whiting M.C. and Woodward R. B. J. Am. Chem. Soc. 1952, 74, 2125- 2126.

[2] Wilkinson G. J. Am. Chem. Soc. 1952, 74, 6149-6150. 
[3] Fischer E.O. and Pfab W.Z. Naturforsch. 1952, 76, 377-379.

[4] Kealy T.J. and Pauson P.L. Nature. 1951, 168, 1039-1040.

[5] Miller S.A., Tebboth J.A. and Tremaine J.F. J. Chem. Soc. (London) 1952, 632-635.

[6] Molina P., Ta'rraga A., Curiel D. et Vel M.D. Journal of Organometallic Chemistry. 2001, 258, 637.

[7] Yamaguchi T., Takahashi K. et Komura T. Electrochimica Acta. 2001, 46, 2527.

[8] Vilas-Boas M., Pereira E. M., Freire C. and Hillman A. R. Journal of Electroanalytical Chemistry. 2002, 538, 47.

[9] Simenel A. A., Kuzmenko Y. V., Morozova E. A., Ilyin M. M., Gun'ko I. F. and Snegur L. V. Journal of Organometallic Chemistry. 2003, 688, 138.

[10] Bard A.J. and Faulkner L.R. 2001, Electrochemical Methods: Fundamentals and Applications, 2nd Ed, Wiley, New York, USA, 226-260 p.

\section{How to cite this article}

Neghmouche N S, Khelef A and Lanez T. Electrochemistry characterization of ferrocene/ferricenium redox couple at glassy carbon electrode. J Fundam Appl Sci. 2009, $1(2), 23-30$. 